\title{
Investigations on Surface Behavior of Electro-Less Nickel Phosphorus Coatings with Nano Additives on Magnesium Alloy Used In Automotive Applications
}

\author{
Motilal Lakavat *1, Amiya Bhaumik*2, Elansezhian Rasu ${ }^{* 3}$ \\ ${ }^{1} \mathrm{PhD}$ Scholar, Lincoln University College, Selangor Darul Ehsan, Malaysia \\ ${ }^{2}$ Professor, Department of Mechanical Engineering, Lincoln University College, Selangor Darul Ehsan, Malaysia. \\ ${ }^{3}$ Professor, Department of Mechanical Engineering, Pondicherry Engineering College, Pondicherry, India.
}

\begin{abstract}
To enhance the damage and corrosion behaviour for alloys, the coating is found because of the maximum fitted technique. Mgbased alloys have a good range of business application. These alloys show a high specific strength but bad attire and corrosion resistance. A standard coating of $\mathrm{Cu}, \mathrm{Ni} \& \mathrm{Zn}$ etc. provides a physical barrier against the wear and tear rate and corrosion attack of magnesium substrate. In the recent study, plating Ni-P was thru going on AZ91 composite by immersing samples into Nickel sulphate bath in the existence of surfactants. The study of the mechanism of Ni-P deposits was studied utilizing SEM. Ni-P coating was coated consistently within the existence of surfactants. Result of surfactant and Result of $\mathrm{Nano}^{-a d d i t i v e s ~} \mathrm{ZnO}_{2} \mathrm{Al}_{2} \mathrm{O}_{3}$ and $\mathrm{SiO}$ with various quantities were examined. $0.5 \mathrm{~g} / \mathrm{l}$ Nano $\mathrm{Al}_{2} \mathrm{O}_{3}$ additive-enhanced the deposition of Ni-P on $\mathrm{AZ} 91$ magnesium composite and hereafter the similar consequences are detected just in case of $\mathrm{SiO}$ accumulation. Effect of $\mathrm{ZnO}$ was also noticed. So is extremely clear that Ni-P coating is extremely effective to scale back the corrosion and rise the wear and tear behaviour if it's used together with Nano additive and therefore the surfactants.
\end{abstract}

Keywords

Nano-additives, Coating, surfactants, Scanning Electron Microscope

Article Received: 10 August 2020, Revised: 25 October 2020, Accepted: 18 November 2020

\section{Introduction}

Amid the numerous materials existing for the automotive and aerospace industry, a Magnesium alloy overcomes a significant place. Mg alloys show lower density, higher exact strength and exceptional machinability $[1,2]$. However, despite these properties, these alloys have a susceptibility to corrosion in a moist atmosphere and thus they have restricted application in the areas where high wear resistance is vital [3]. The coating is found as the utmost suitable technique to progress the wear characteristic [4]. Magnesium alloys are light in weight but their applications are restricted in engineering industries due to the poor wear \& corrosion resistance. The difficult of corrosion was enhanced by the overview of pure alloys [5]. Alloying develops the overall corrosion behaviour, but no important development has been detected in galvanic corrosion $[6,7]$. To solve this concern proper coating is vital [8]. The Ni-P coating is the exact operative for reduction corrosion but the task is to do the coating by the effective way. For that accumulation of Nano additives and the separate surfactants on $\mathrm{Ni}-\mathrm{P}$ deposition was used and their result considered in this determination by Sun et. al. [9]. Electroless plating technique outcomes in the decrease of a well, smooth and uniform surface that gives good surface roughness properties, wear resistance and defence beside corrosion [10-12]. In recent times researchers have their attention towards Ni-P coatings which includes the effect of phosphorous content on structure and surface morphology. Ni-P coating has categorized and based on content phosphorous. Higher content of phosphorous (higher than $8 \%$ ) tells the finest corrosion properties and suggested for the environment where serious corrosion happens. Although a coating with lower phosphorus contents (lesser than $3 \%$ ) shows Deprived corrosion resistance and noble wear properties. Thus, Magnesium alloys Corrosion resistance not only depends lone on the content of phosphorous. According to Mimani et.al. [13], the corrosion behaviour of amorphous state can be focused by the grade of amorphous state, the amount of inner stress and the weight percentage of content phosphorus. Many researchers have reported the coating performance in different environments concerning the amount of phosphorus used. To additional advance, the coating completing present days scientists are through Nanoparticles along with 
electroless Ni-P coating. The Nanoparticles like $\mathrm{Al}_{2} \mathrm{O}_{3}, \mathrm{SiO}_{2}, \mathrm{TiO}_{2}$ etc. are normally further in an electrolytic bath to formulate the electroless Ni-P Nanoparticle coating. Though Nano additive advances the corrosion behaviour and wear execution of coating nevertheless still it has few tasks. The first thing is the identical distribution of Nanoparticles and the next one is the agglomeration which affects the stability of Nano

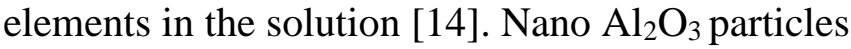
are used by several researchers because of high strength and good stability. These particles are relatively cheap and exhibit good hardness [15]. These particles are generally used for copper and steel substrate and slight work has been specified on Magnesium alloys. The objectives of this effort are to work the Mg AZ91D composites (Mg with $1 \%$ wt MWCNT-(1\%wt) Al203) which can be used as a substrate material and the $\mathrm{Al} 2 \mathrm{O} 3, \mathrm{ZnO}$ $\& \mathrm{SiO}$ are used as Nano additives for checking their outcome. Tests are conducted to get the effect of Nano additives on the properties of mechanical of less electro Ni-P Coated $\mathrm{Mg}$ composite and their outcomes are presented and discussed in the further section.

\section{Experimental details}

A. Preparation of specimen for the test

Substrate materials selected for the coating were magnesium $(\mathrm{Mg})$ composite comprising 1 wt. \% of MWCNT and 1 wt. $\%$ of $\mathrm{Al}_{2} \mathrm{O}_{3}$ which was bought from Mangaluru, India. The sample as shown in Figure 1 was cutting through wire EDM for Ni-P coating. Rectangular $(8 \mathrm{~mm}$ x $26 \mathrm{~mm}$ x 8 $\mathrm{mm}$ ) sample of $\mathrm{Mg}$ composite are first ground increasingly with $\mathrm{SiC}$ abrasive paper have 400 500, 600, 800, 1500 and 2000, mesh to achieve an acceptable surface uniformity. Similarly, for the corrosion test, the sample is cut to dimension (10 $\mathrm{mm} \times 20 \mathrm{~mm} \times 8 \mathrm{~mm}$ ).

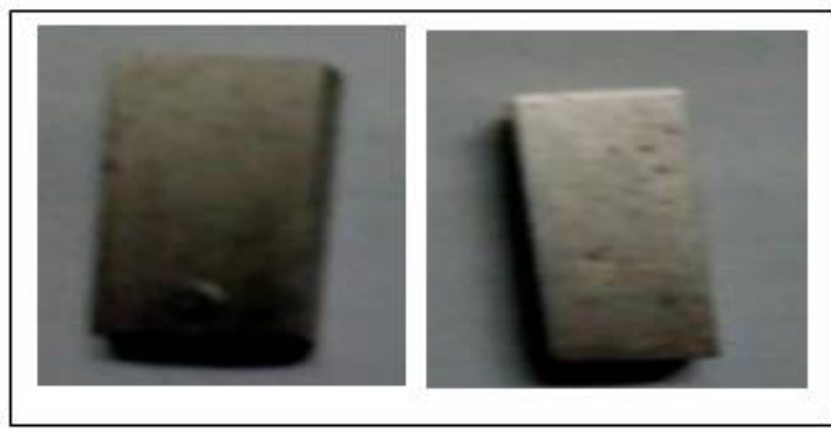

Figure1. The sample preparation for the test.

\section{B. Pretreatment process}

During the process of pre-treatment, the acetone is used for the cleaning of the substrate. Extra, alkaline cleaned with $\mathrm{NaOH}(45 \mathrm{~g} / \mathrm{L})$ is ready follows by $\mathrm{Na}_{3} \mathrm{PO}_{4}$ Trisodium orthophosphate (10 $\mathrm{g} / \mathrm{L})$ for 20 minutes; at $65^{\circ} \mathrm{C}$ temperature. Subsequently, it is continued by acid treatment with chromium tri-oxide $(125 \mathrm{~g} / \mathrm{L})$ and nitric acid $(100 \mathrm{ml} / \mathrm{L})$ for $40 \mathrm{sec}$. Finally, the fluoride activation is done with hydro fluoride at 10 minutes at room temperature. The procedure is followed as per the literature [16]. The setup shows in Figure 2.

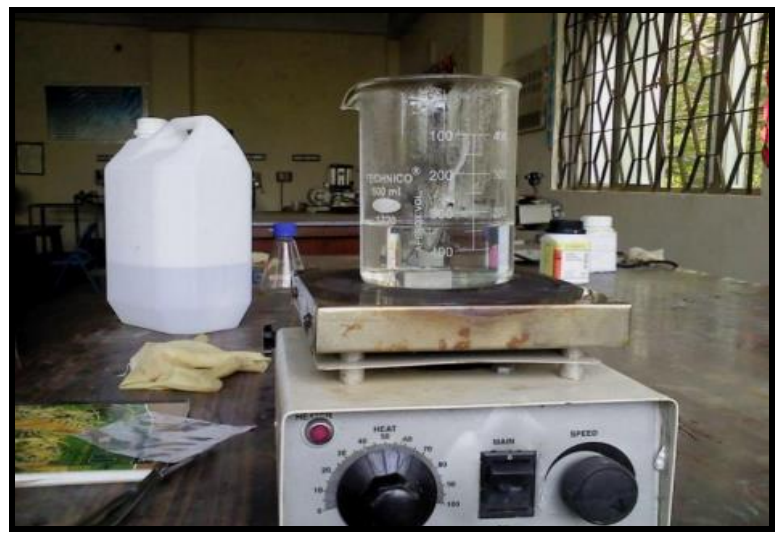

Figure2. Alkaline cleaning setup.

\section{Electroless nickel coating bath and operating conditions}

The coating bath consists of:

(a) Nickel Sulphate (26 g/L),

(b) Sodium hypo-phosphate (30 $\mathrm{g} / \mathrm{L})$ as reducing agent,

(c) Sodium acetate $(16 \mathrm{~g} / \mathrm{L})$ as stabilizer and

(d) Ammonium hydrogen difluoride $(8 \mathrm{~g} / \mathrm{L})$ as the complexing agent.

The surfactant SLS $(1.2 \mathrm{~g} / \mathrm{L})$ is added in the solution earlier EN deposition. The stabilizer thiourea (1ppm) is added into the bath when the reaction is stable. Process parameter like Temperature, $\mathrm{pH}$ and effect of Surfactant concentration changes. The $\mathrm{pH}$ level is modified by adding $\mathrm{NaOH}$ pallets. The temperature and $\mathrm{pH}$ values are changing at 3 different levels 4 to 5,6 to 7 and 8 to 9 and $70^{\circ} \mathrm{C}, 85^{\circ} \mathrm{C}$ and $90^{\circ} \mathrm{C}$ respectively. The surfactant SLS is used and its concentration was the change from 0 to $1.2 \mathrm{~g} / \mathrm{L}$. It is observed that $\mathrm{pH}$ value 6-7, temperature preserved at $85^{\circ} \mathrm{C}$ and SLS $(1.2 \mathrm{~g} / \mathrm{L})$ offers improved coating with Nano additive [17]. The 
composition of the coating baths and the varying percentage of Nano additives are specified in tables I and II.

Table I. Compositions of bath for electroless Ni $-P$ coating

\begin{tabular}{|c|c|c|c|}
\hline \multirow{2}{*}{ Particulars } & Bath $\mathbf{A}$ & $\begin{array}{c}\text { Bath } \\
\text { B }\end{array}$ & Bath C \\
\cline { 2 - 4 } & \multicolumn{2}{|c|}{ Quantity(g/L) } \\
\hline $\mathrm{NiSO}_{4} 6 \mathrm{H}_{2} \mathrm{O}$ & 28 & 28 & 28 \\
\hline $\begin{array}{c}\mathrm{Na} \mathrm{H}_{2} \mathrm{O}_{2} \mathrm{PO}_{2} \\
\mathrm{H}\end{array}$ & 33 & 33 & 33 \\
\hline $\mathrm{HF}(40 \%, \mathrm{v} / \mathrm{v})$ & $12 \mathrm{ml}$ & $12 \mathrm{ml}$ & $12 \mathrm{ml}$ \\
\hline $\mathrm{NaC}_{2} \mathrm{H}_{3} \mathrm{O}_{2}$ & 18 & 18 & 18 \\
\hline $\mathrm{NH}_{4} \mathrm{HF}_{2}$ & 8 & 8 & 8 \\
\hline $\mathrm{NaCl}_{2} \mathrm{H}_{25} \mathrm{SO}_{4}$ & 1.3 & 1.3 & 1.3 \\
\hline $\mathrm{Thiourea}$ & $1 \mathrm{ppm}$ & $1 \mathrm{ppm}$ & $1 \mathrm{ppm}$ \\
\hline $\begin{array}{c}\mathrm{Nano} \mathrm{Al}_{2} \mathrm{O}_{3}, \\
40 \text { nm }\end{array}$ & $00.5-2$ & - & - \\
\hline $\begin{array}{c}\text { Nano } \mathrm{ZnO}, 50 \\
\mathrm{~nm}\end{array}$ & - & $00.5-2$ & - \\
\hline $\begin{array}{c}\text { Nano } \mathrm{SiO}, 25 \\
\mathrm{~nm}\end{array}$ & - & - & $00.5-2$ \\
\hline
\end{tabular}

Table II. Concentration details of the Nano additives employed

\begin{tabular}{|l|l|l|l|}
\hline $\begin{array}{l}\text { Element } \\
\text { Line }\end{array}$ & Weight(\%) & Atom(\%) & Formula \\
\hline O K & 4.29 & 11.77 & $\mathrm{O}$ \\
\hline $\mathrm{Al} \mathrm{K}$ & 0.62 & 0.88 & $\mathrm{Al}$ \\
\hline $\mathrm{P} \mathrm{K}$ & 8.49 & 12.20 & $\mathrm{P}$ \\
\hline Ni K & 86.60 & 75.15 & $\mathrm{Ni}$ \\
\hline Total & 100 & 100 & \\
\hline
\end{tabular}

\section{Electroless coating procedure}

The coating is put on for $1 \mathrm{hr}$ with a total bath volume of $400 \mathrm{ml}$ is shown in Fig 3 and Fig 4. The $\mathrm{Al}_{2} \mathrm{O}_{3}$ (40 nm size), $\mathrm{SiO}$ ( $25 \mathrm{~nm}$ average size ) and $\mathrm{ZnO}$ (50 nm size) nanoparticle are added to the appropriate solutions (Table1) to study the comparisons of tribological properties. Ultra sonication method was applied to minimalize the agglomeration of the $\mathrm{Al}_{2} \mathrm{O}_{3}, \mathrm{SiO}$ and $\mathrm{ZnO}$ which was applied for 15 mins. The magnetic moving at a constant speed of $100 \mathrm{rpm}$ was performing for 60 minutes for electroless deposition [18]. The $\mathrm{pH}$ levels are altered by adding $\mathrm{NaOH}$ pallet. Image of the coated sample is shown in Figure5.

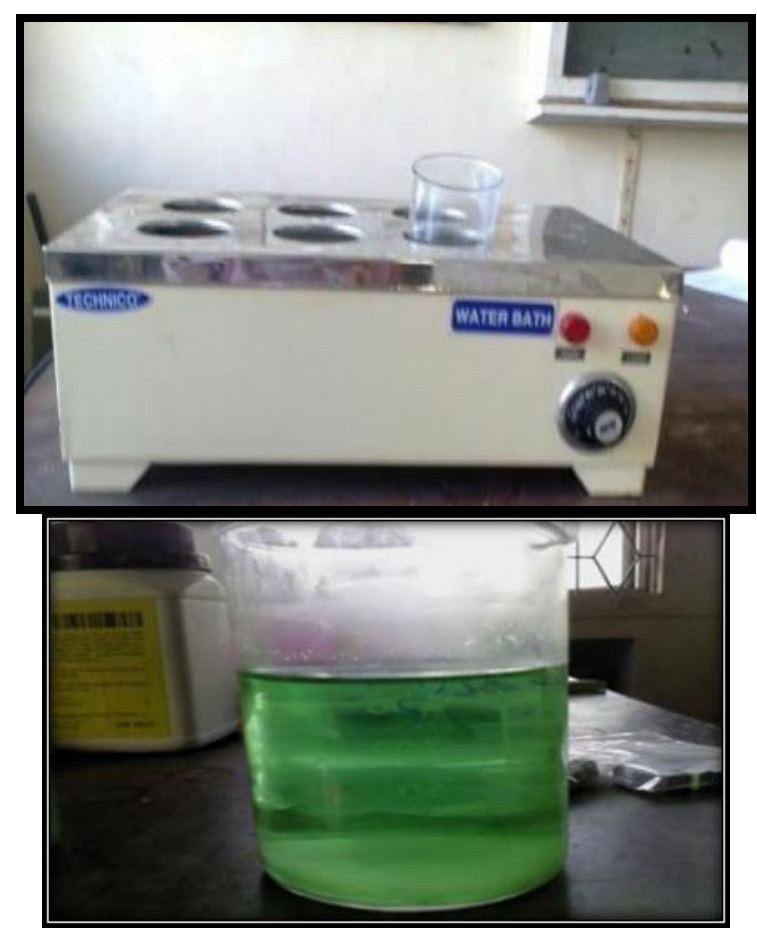

Figure3. Experimental set up used for EN deposition. Figure4. Bath preparation for the test.

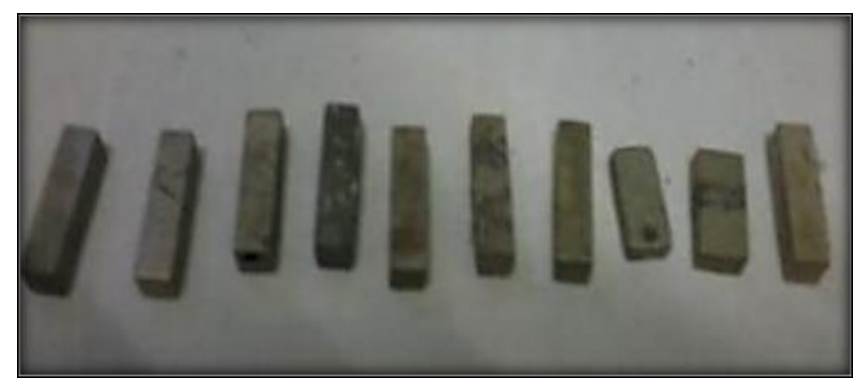

Figure5. Coated samples used for the test

\section{E. Scanning of electron microscopy}

SEM was utilized for the surface topography. The study has given the details about the texture, crystalline structure, orientation and the sample of chemical composition.

\section{Results and discussion}

A. Result of $\mathrm{Al}_{2} \mathrm{O}_{3}$ difference The SEM image of deposit taken at an unlike $\mathrm{Al}_{2} \mathrm{O}_{3}$ percentage of bath solutions for magnesium composite substrate are shown in Figure6. Figure6 (a) to (d) show the EDAX image represent the existence of Nano $\mathrm{Al}_{2} \mathrm{O}_{3}$ particle. It is further observed from beyond mentioned EDX image, the $\mathrm{Al}_{2} \mathrm{O}_{3}$ particle is similarly spread in $\mathrm{EN}$ deposit and this is taken in a high 
percentage of Nano additive related to a low percentage. Hereafter, it is noticed that the accumulation of changing percentage of $\mathrm{Al}_{2} \mathrm{O}_{3}$ Nano additive, increases coating uniformity (shown in Figure6). The introduction of the SLS (sodium lauryl sulphate) anionic surfactant into the coating bath results into deagglomeration of Nano-alumina particles as shown in Figure6 (d). The morphology of different coatings deposited from the bath solution of different $\% \quad \mathrm{Al}_{2} \mathrm{O}_{3}$ is investigated. Maximum consistency in the microstructure was found in coatings taken at $2 \% \quad \mathrm{Al}_{2} \mathrm{O}_{3}$ Nano additives, (Figure6 (d)). The non-constant of the surface due to the different $\% \mathrm{Ni}$ in the coating.

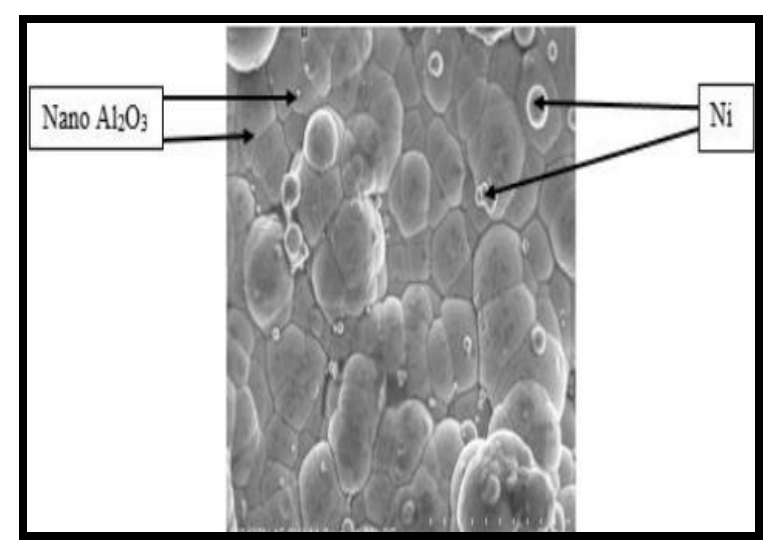

A

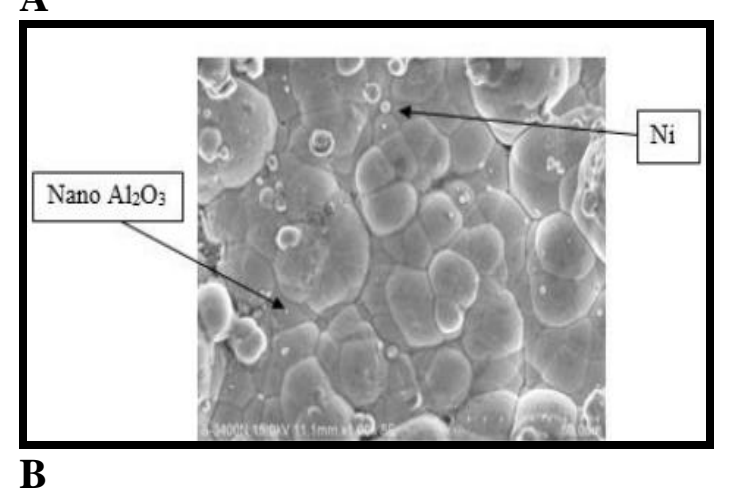

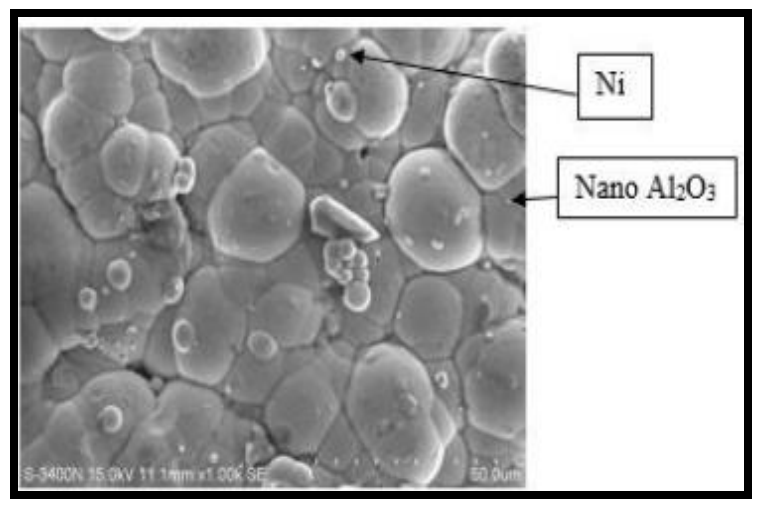
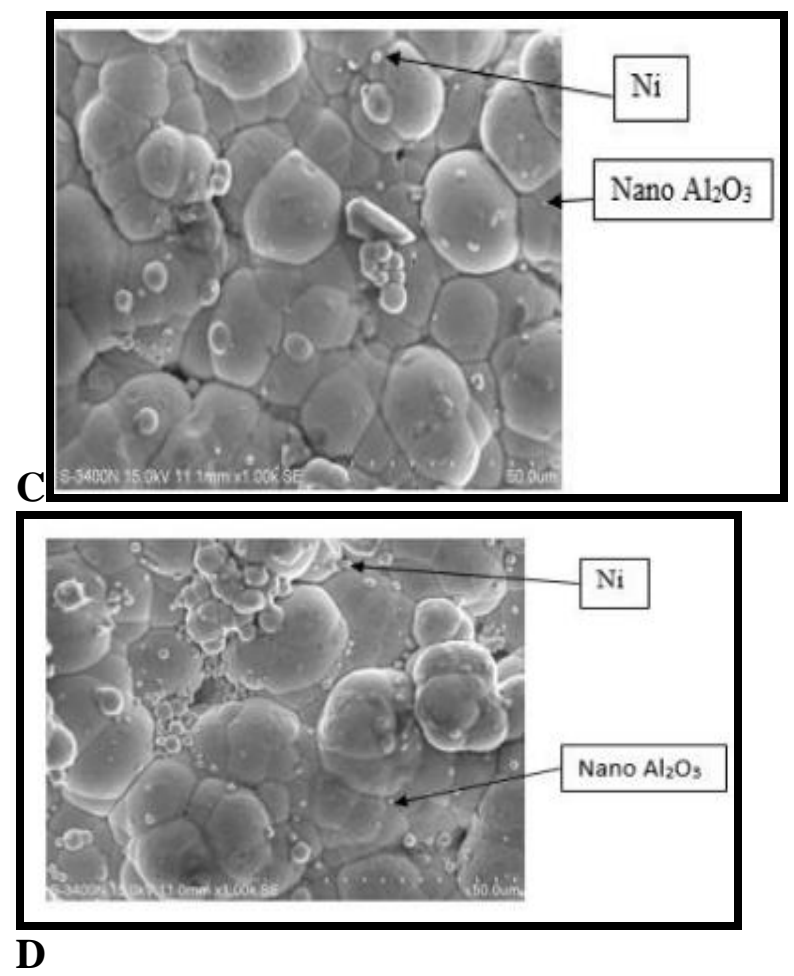

Figure6. SEM micrograph (1000X) of electro less Ni-P coating on magnesium (Mg) composite reinforced with multiwall carbon nanotube (MWCNT) at varying \% of $\mathrm{Al}_{2} \mathrm{O}_{3}$ (a) $0.1 \%$ (b) $0.5 \%$ (c) $1 \%$ (d) $2 \%$, with surfactant (SLS)

\section{B. Elemental analysis-EDAX}

The $\mathrm{Mg}$ composite with an increasing percentage of $\mathrm{Al}_{2} \mathrm{O}_{3}$ of EDAX Pattern of nickel electroless Nano additive shown in Figure7.The presence of nickel in varying percentage is seen as sharp peaks within the all the EDAX spectrum, while the spectra of $\mathrm{Al}_{2} \mathrm{O}_{3}$ Nanocoatings shown in Figure7 (a, b, c, d) indicate typical peaks of $\mathrm{Al}$ and Oxide in ascending proportion indicate the consistency adherent and porosity free surface with an increased percentage of $\mathrm{Al}_{2} \mathrm{O}_{3}$ Nano additive on the Substrate. 


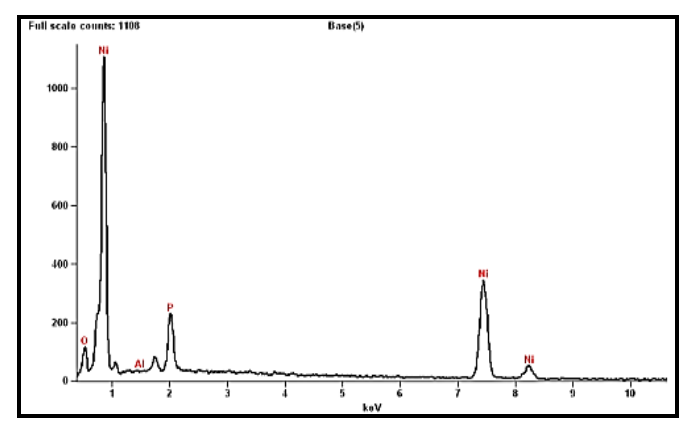

(a)

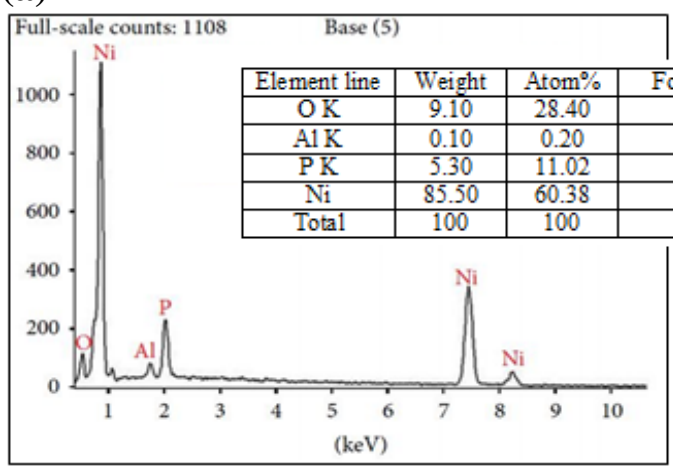

(b)

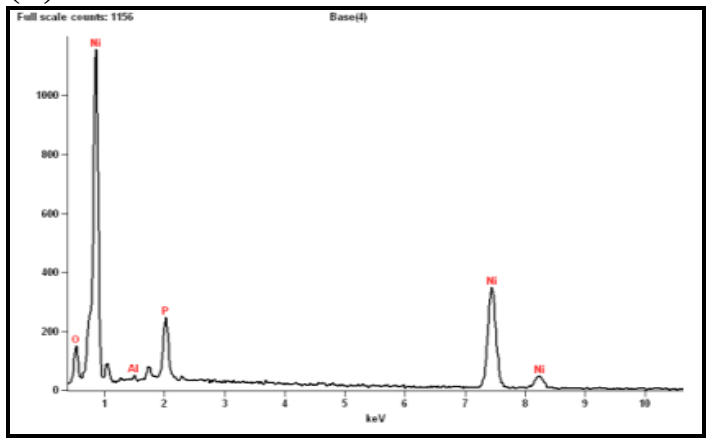

(c)

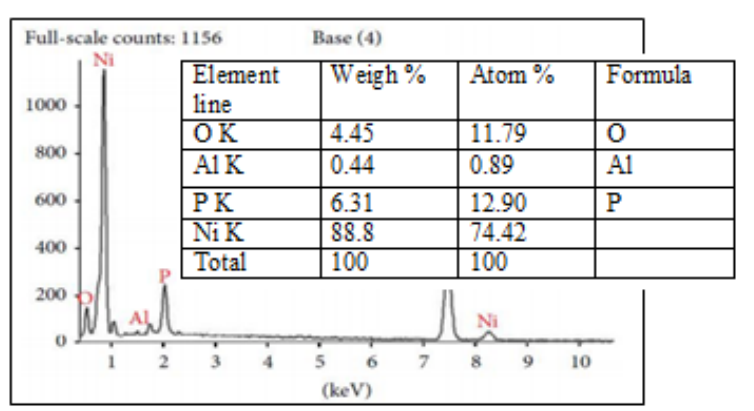

(d)

Figure7. EDAX spectrum showing presence of Ni-P coated on magnesium (Mg) composite reinforced with multiwall carbon nanotube (MWCNT) at varying $\%$ of $\mathrm{Al}_{2} \mathrm{O}_{3}$ (a) $0.1 \%$ (b) $0.5 \%$ (c) $1 \%$ (d) $2 \%$, with surfactant (SLS).

\section{Effect of $\mathrm{SiO}$ variation}

Different percentage of $\mathrm{SiC}$ Nano additives display quiet different surface morphologies (shown in figure 8). The morphology of coating is a deposit from the bath solution of various $\% \mathrm{SiO}$ is investigated. Figure8 (a) to (d) shows the uniform distribution of $\mathrm{SiO}$ particles within the coating. The nickel particles deposited on the surface substrate expedite the method and decreases the contacts angle which eventually results in the superior wettability on the substrate. The coating thus produced would always have an honest bonding to the substrate. The agglomeration of Nanoparticle is prohibited using anionic SLS- (sodium lauryl sulphate surfactant). By comparing the addition of Nano additive with one another, a compressed and defect-free composite coating is obtained with $2 \%$ $\mathrm{SiO}$ amount. It implies that with increase $\mathrm{SiO}$ web page, uniformity increases.

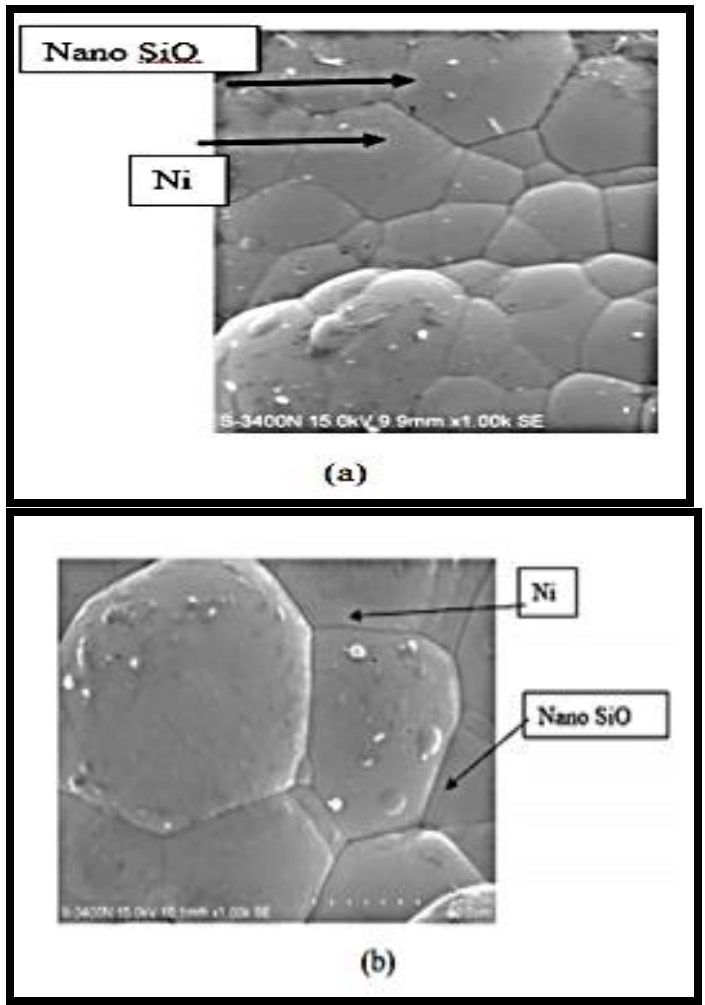




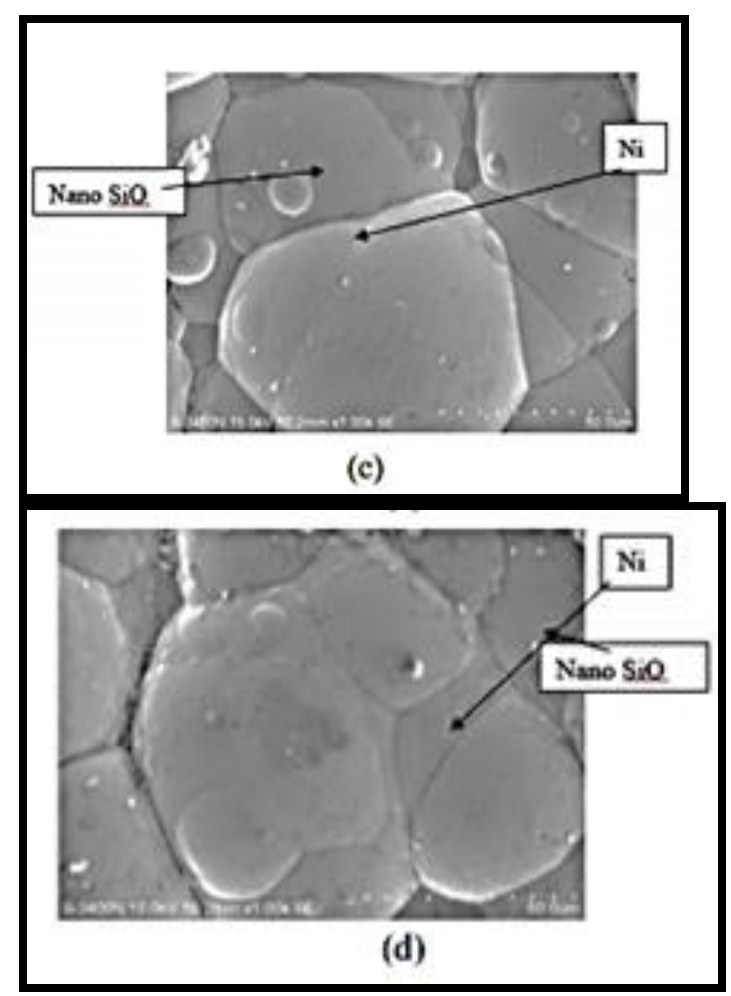

D. Elemental analysis of mg composite - EDAX The EDAX pattern of the electroless nickel coated $\mathrm{Mg}$ composite with an increased percentage of $\mathrm{SiO}$ Nano additive are shows in Fig.9. An element analysis made on the surface (Fig.9 (a)-(d)) indicates that $\mathrm{Ni}, \mathrm{P}, \mathrm{Si}$ and $\mathrm{O}$ elements exist in the coating. The presence of nickel in varying percentage is seen as sharp peaks in the all the EDAX spectrum, while the spectra of $\mathrm{SiC}$ Nanocoatings shown in Figure9 (a),(b),(c),(d) indicates typical $\mathrm{Si}$ and $\mathrm{O}$ in ascending proportions contributing to the uniformity, adherent and porosity free smooth surface on the Substrate.

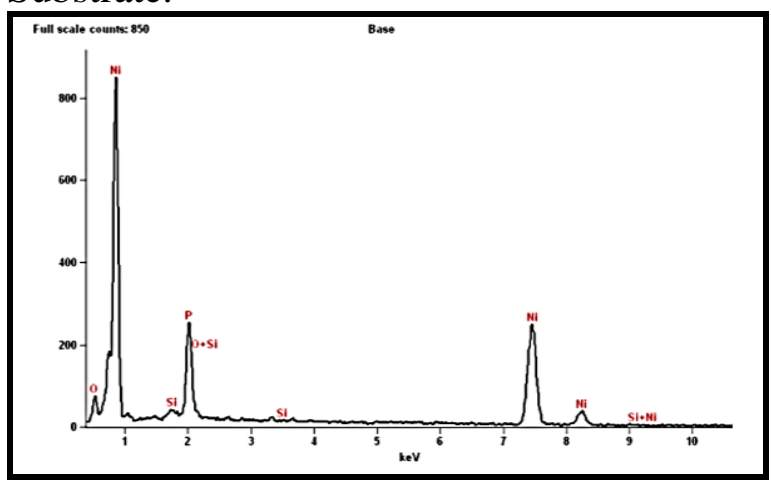

(a)

Base (2)

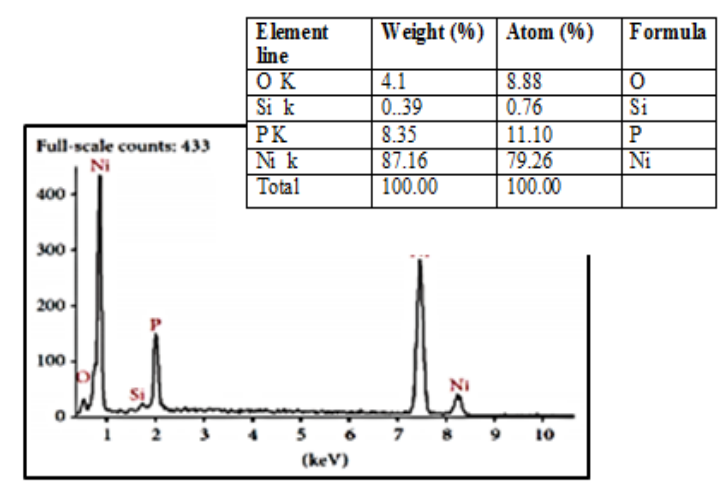

(b)

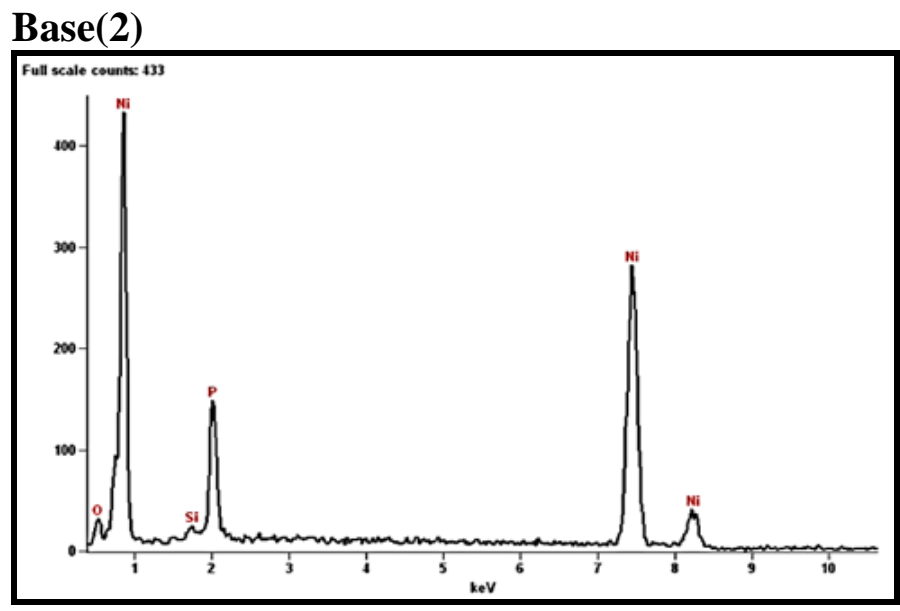

(c)

\section{Base}

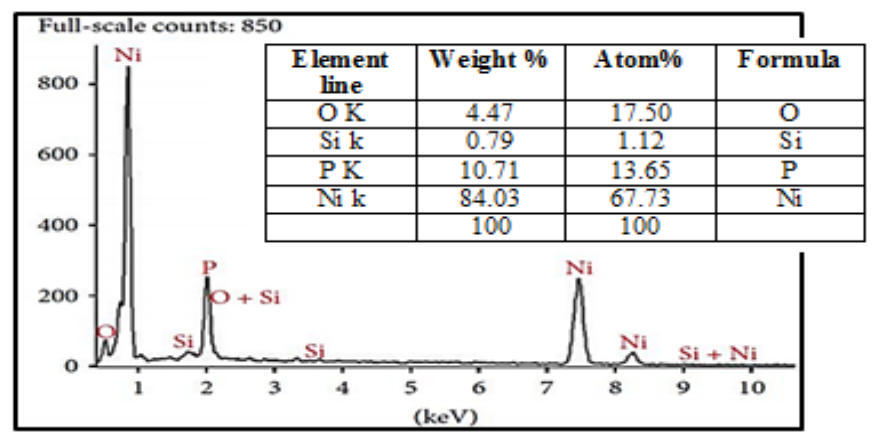

(d)

Fig9. EDAX spectrum showing presence of Ni-P coated on magnesium $(\mathrm{Mg})$ composite reinforced with multiwall carbon nanotube (MWCNT) at varying $\%$ of $\mathrm{SiO}$ (a) $0.1 \%$ (b) $0.5 \%$ (c) $1 \%$ (d) $2 \%$, with surfactant (SLS).

\section{E. Effect of $\mathrm{ZnO}$ variation}

Fig.10. (a), (b), (c) and (d) is showing the incorporation of higher \% of $\mathrm{ZnO}$ Nano-particles in the coating has resulted in a rougher surface ( $(\mathrm{Ra}$ value $=1.26)$, of for composite coatings in comparison to low \% of $\mathrm{ZnO}$. It is similarly seen that the surge in the amount of the $\mathrm{ZnO}$ Nanoparticles in the Ni-P matrix happened to attain an 
additional uneven surface (Fig. 10- b and c). Since the rougher morphology might be a proof for the existence of the $\mathrm{ZnO}$ Nano-particle at the surface, it has observed the rise in nanoparticles concentration in the bath tends to increasing volumes of Nano-particles incorporation in the coating.

\section{F. Elemental analysis of mg composite - EDAX}
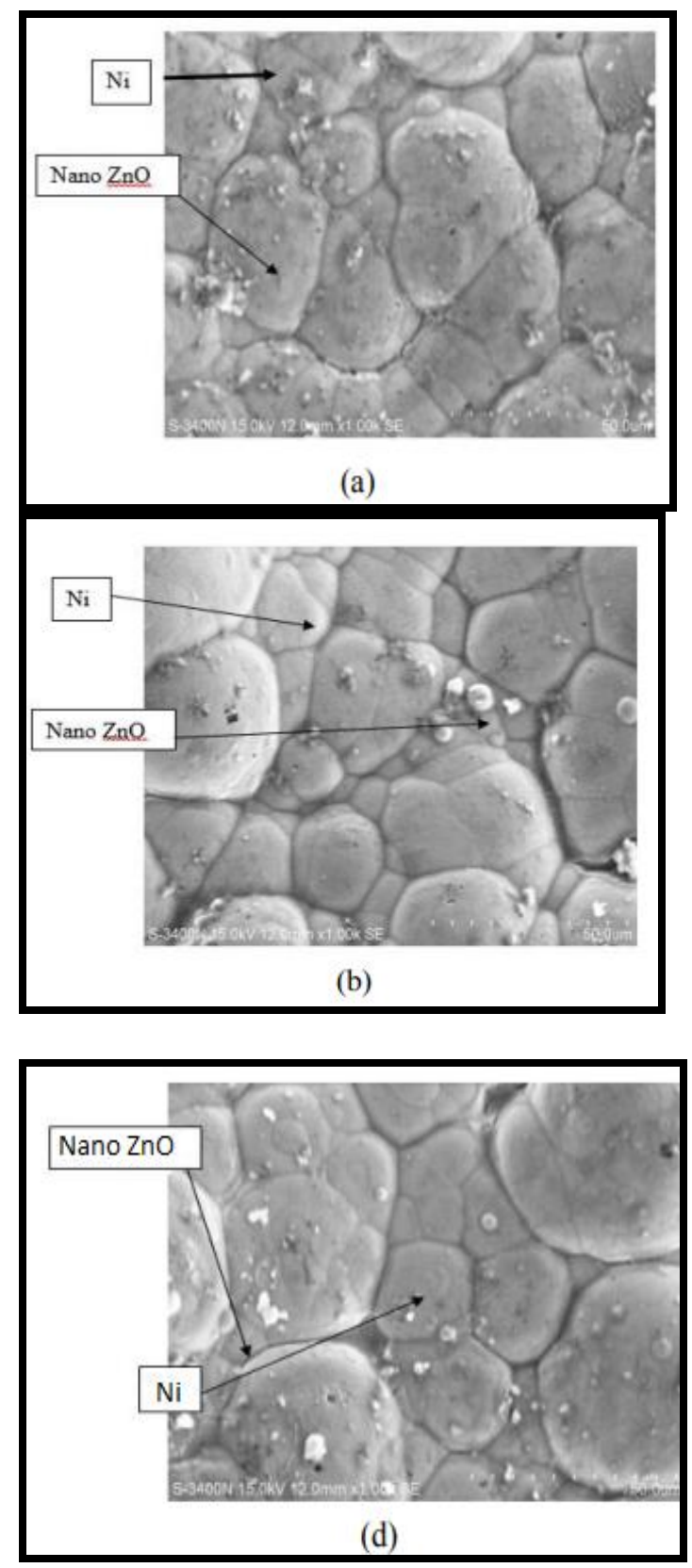

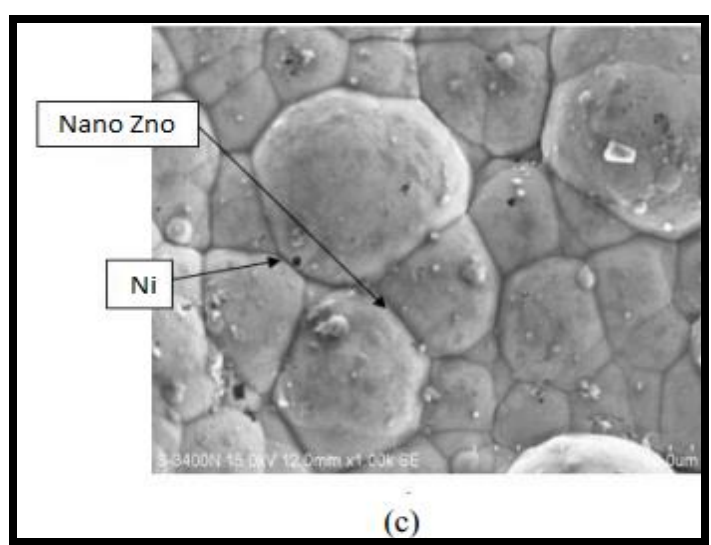

Fig10. SEM micrograph (1000X) of electro less Ni-P coating on magnesium (Mg) composite reinforced with multiwall carbon nanotube (MWCNT) at varying \% of $\mathrm{ZnO}$ (a) $0.1 \%$ (b) $0.5 \%$ (c) $1 \%$ (d) $2 \%$, with surfactant (SLS).

\section{F. Elemental analysis of mg composite - EDAX}

The EDAX patterns of the electroless nickel coated $\mathrm{Mg}$ composite with increasing percentages of $\mathrm{ZnO}$ Nano additives shown in Figure11 a component analysis made on the surface (see Figure 11 (a)-(d)) indicates that $\mathrm{Ni}, \mathrm{P}, \mathrm{Zn}$ and $\mathrm{O}$ elements exist within the coating. it's shown that Nanoparticles incorporation within the Ni-P matrix's affects the structure of the EN coating and also the EDAX spectrum of both low and high $\%$ of $\mathrm{ZnO}$ shows the presence of $\mathrm{ZnO}$ and increased $\mathrm{P}$ content. The increase in $\mathrm{P}$ content due to the addition of surfactants in $\mathrm{EN}$ bath. Surfactant promotes $\mathrm{P}$ content within the coating as reported in Elansezhian et al (2008). While the spectra of Nano ZnO coating shown in Fig11-(b) \& (d) indicates typical $\mathrm{Zn}(1.67$ to $3.05 \mathrm{Wt} . \%)$ in ascending proportion to finish up within the formation of the rougher surface because of high agglomeration of $\mathrm{ZnO}$ particles. Excess $\mathrm{ZnO}$ Nanoparticle in amorphous phase could increase the resistance of corrosion of $\mathrm{EN}$ coated composites. Hereafter, Variation in corrosion resistance of EN coating as part of $\mathrm{ZnO}$ with surfactant (SLS) in EN bath is the study and also the effects are analyzed within the next section 


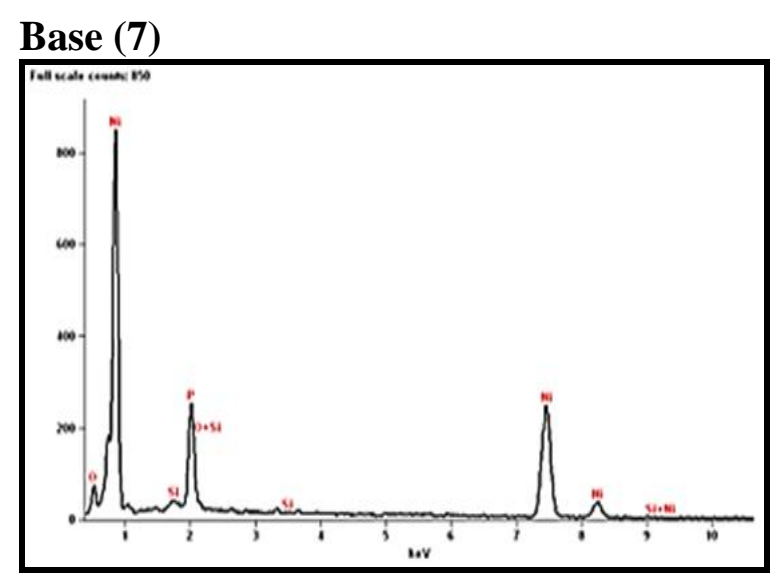

(a)

\section{Base(8)}

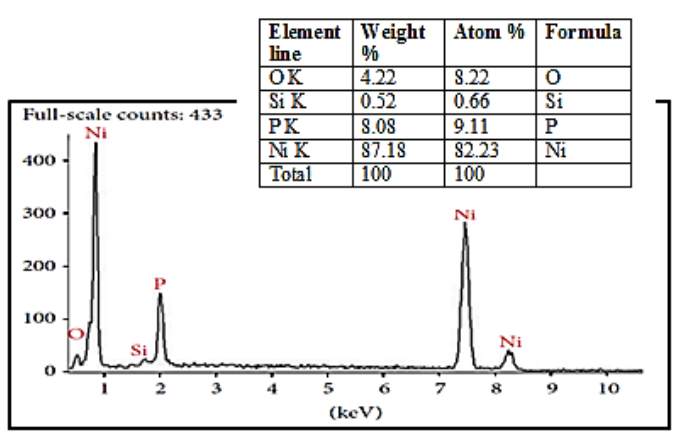

(b)

\section{Base (8)}

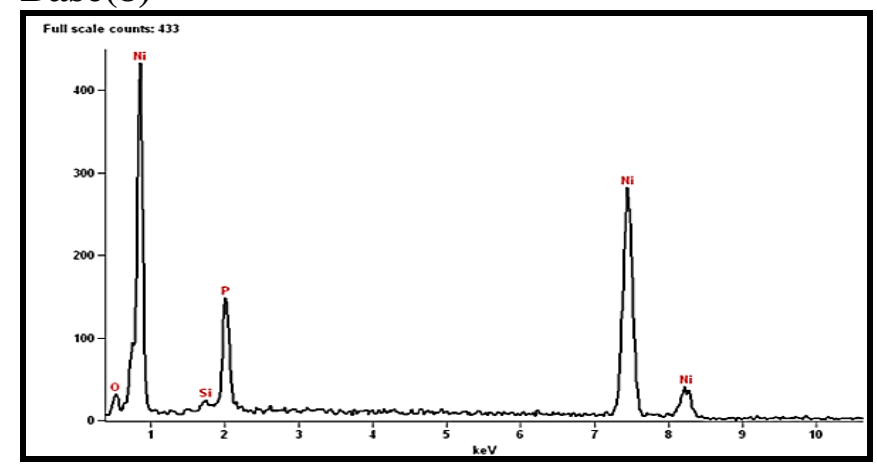

(c)

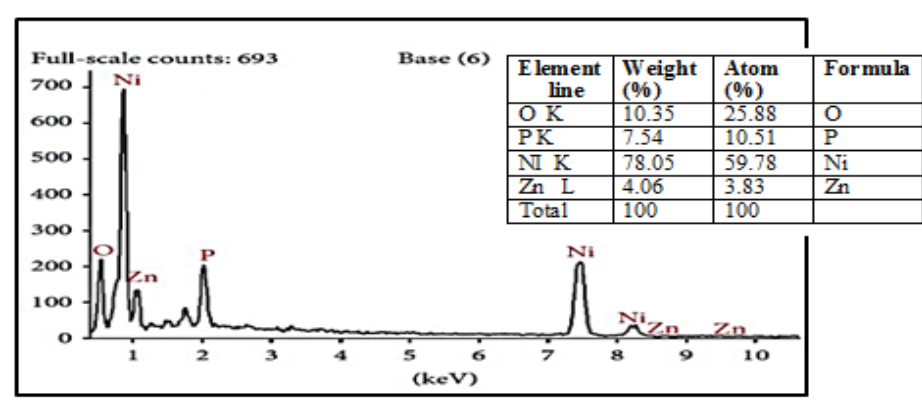

(d)

Fig11. EDAX spectrum showing presence of Ni$P$ coated on magnesium (Mg) composite reinforced with multiwall carbon nanotube (MWCNT) at varying \% of $\mathrm{ZnO}$ (a) $0.1 \%$ (b) $0.5 \%$ (c) $1 \%$ (d) $2 \%$, with surfactant (SLS).

\section{G. SEM Ni-P images of Coated Mg composite without surfactant and Nano additive}

The SEM micrographs in Figure12 show the nonconsistency deposition of $\mathrm{Ni}$ particles on the substrate. Deprived of the existence of anionic surfactant SLS-sodium lauryl sulphate, the agglomerations of Nanoparticle are visible. It is decided that the surface of morphology EN coated $\mathrm{Mg}$ composite substrate lacking Nano additive and surfactant have lower surface texture when related with coatings with $2 \%$ Nano additives.

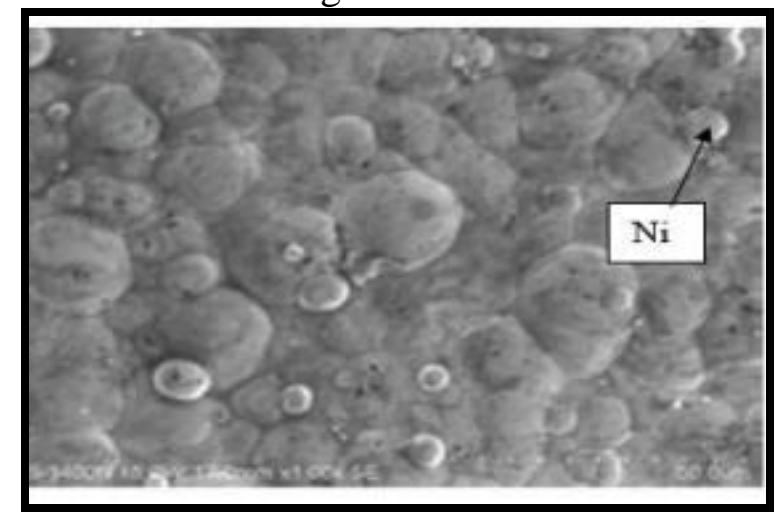

Figure12. (1000×) SEM micrograph of EN coated Mg composite without surfactant and Nano additives.

\section{Conclusion}

On AZ91 magnesium the Electroless Ni-p Electroless coating is carried successfully overall progress has found with surfactant accumulation through enhanced distribution was reached with a minimum amount of SLS and surfactant. The process of pretreatment benefits in avoiding galvanic corrosion and it plays a very significant role. Thus entire Ni-p coatings initially pretreated earlier applying on $\mathrm{mg}$ substrate. The coatings Electroless Ni-P was successfully carried out on AZ91 magnesium the pretreatment helps to avoid galvanic corrosion with a minimum amount of SLS \& surfactant better distribution was attained it plays a significant role. With the addition of surfactant, a general improvement has been obtained consequently, pre-treated all Ni-P coating applied on magnesium substrate earlier. Expedite the electroless reaction Nano additive acted as catalyst Nano-additives enabled the better distribution of Ni-P coating. The surface tension between the eventually abridged the chances of cluster and particles by Surfactants lessen on AZ91 magnesium substrate $\left(\mathrm{Al}_{2} \mathrm{O}_{3}, \mathrm{SiO}\right.$, and $\mathrm{ZnO}$ ) compare to others the $\mathrm{SiO}$ provides most 
uniform particle distributions. It was found that $\mathrm{ZnO}$ and $\mathrm{Al}_{2} \mathrm{O}_{3}$ were capable of also equally to do the same. The wider reaction generated by Nano additive site on magnesium and the serve substrate purpose is uniform coating distribution on substrate. It is concluded that along with surfactants the Nano-additives addition helps the distribution and deposition of coating for industrial applications which surges usefulness of coating.

\section{References}

[1] Yamashita, Z. Horita, and T. G. Langdon, "Improving the mechanical properties of magnesium and a magnesium alloy through severe plastic deformation," Materials Science and Engineering: A, vol. 300, pp. 142-147, 2001.

[2] A. Singh and S. P. Harimkar, "Laser surface engineering of magnesium alloys: a review," Jom, vol. 64, pp. 716-733, 2012.

[3] W. Kasprzak, F. Czerwinski, M. Niewczas, and D. Chen, "Correlating hardness retention and phase transformations of $\mathrm{Al}$ and $\mathrm{Mg}$ cast alloys for aerospace applications," Journal of Materials Engineering and Performance, vol. 24, pp. 1365$1378,2015$.

[4] L. Cisar, Y. Yoshida, S. Kamado, Y. Kojima, and F. Watanabe, "Development of High Strength and Ductile Magnesium Alloys for Automobile Applications," Materials Science Forum, vol. 419-422, pp. 249-254, 2003.

[5] J. Tan and M. Tan, "Dynamic continuous recrystallization characteristics in two-stage deformation of $\mathrm{Mg}-3 \mathrm{Al}-1 \mathrm{Zn}$ alloy sheet," Materials Science and Engineering: A, vol. 339, pp. 124-132, 2003.

[6] P. J. Blau and M. Walukas, "Sliding friction and wear of magnesium alloy AZ91D produced by two different methods," Tribology International, vol. 33, pp. 573-579, 2000.

[7] J. K. Pancrecious, S. B. Ulaeto, R. Ramya, T. P. D. Rajan, and B. C. Pai, "Metallic composite coatings by electroless technique - a critical review," International Materials Reviews, pp. 125, 2018.

[8] S. Xu, S. Kamado, N. Matsumoto, T. Honma, and Y. Kojima, "Recrystallization mechanism of ascast AZ91 magnesium alloy during hot compressive deformation," Materials Science and Engineering: A, vol. 527, pp. 52-60, 2009.

[9] Y.-h. Sun, R.-c. Wang, C.-q. Peng, Y. Feng, and M. Yang, "Corrosion behaviour and surface treatment of superlight $\mathrm{Mg}-\mathrm{Li}$ alloys," Transactions of Nonferrous Metals Society of China, vol. 27, pp. 1455-1475, 2017/07/01/ 2017.
[10] C. K. Lee, "Corrosion and wear-corrosion resistance properties of electroless $\mathrm{Ni}-\mathrm{P}$ coatings on GFRP composite in wind turbine blades," Surface and Coatings Technology, vol. 202, pp. 4868-4874, 2008/06/25/ 2008.

[11] M. Sribalaji, P. Arunkumar, K. S. Babu, and A. K. Keshri, "Crystallization mechanism and corrosion property of electroless nickelphosphorus coating during intermediate temperature oxidation," Applied Surface Science, vol. 355, pp. 112-120, 2015/11/15/2015.

[12] A. Araghi and M. H. Paydar, "Wear and corrosion characteristics of electroless Ni-W-PB4C and Ni-P-B4C coatings," Tribology Materials, Surfaces \& Interfaces, vol. 8, pp. 146153, 2014/09/01 2014.

[13] T. Mimani and S. M. Mayanna, "The effect of microstructure on the Surface and Coatings Technology, vol. 79, pp. 246-251, 1996/02/01/ 1996.

[14] X. L. Ge, D. Wei, C. J. Wang, B. Zeng, and Z. C. Chen, "A study on wear resistance of the Ni-P$\mathrm{SiC}$ coating of Magnesium Alloy," in Applied Mechanics and Materials, 2011, pp. 1078-1083.

[15] Y. Choi, C. Lee, Y. Hwang, M. Park, J. Lee, C. Choi, et al., "Tribological behaviour of copper nanoparticles as additives in the oil," Current Applied Physics, vol. 9, pp. e124-e127, 2009/03/01/ 2009 .

[16] M. Saeedi Heydari, H. R. Baharvandi, and S. R. Allahkaram, "Electroless nickel-boron coating on B4C-Nano TiB2 composite powders," International Journal of Refractory Metals and Hard Materials, vol. 76, pp. 58-71, 2018/11/01/ 2018.

[17] M. Gholizadeh-Gheshlaghi, D. Seifzadeh, P. Shoghi, and A. Habibi-Yangjeh, "Electroless NiP/nano-WO3 coating and its mechanical and corrosion protection properties," Journal of Alloys and Compounds, vol. 769, pp. 149-160, 2018/11/15/ 2018.

[18] L. Bonin, V. Vitry, and F. Delaunois, "The tin stabilization effect on the microstructure, corrosion and wear resistance of electroless $\mathrm{NiB}$ coatings," Surface and Coatings Technology, vol. 357, pp. 53-363, 2019/01/15/ 2019 